\title{
The Decade 1989-1998 in Spanish Psychology: An Analysis of Development of Professional Psychology in Spain
}

\author{
Francisco Santolaya Ochando, Manuel Berdullas Temes, and José Ramón Fernández Hermida \\ Official College of Psychologists
}

\begin{abstract}
In this paper, an overview of the evolution and current situation of professional psychology in Spain is offered. From a historical viewpoint, since the seventies, the profession of psychologist in Spain has advanced significantly in both quality and quantity. There are many different reasons for this development, although in this paper, we highlight two: the introduction of the Psychology Degree and the development of a professional identity due to the influence of an organization such as the "Colegio Oficial de Psicólogos" [COP - Official College of Psychologists, aiso denominated The Spanish Psychological Association]. Our description of the current situation is based on the analysis of the results of 6,765 surveys out of the approximately 28,000 that were sent to members of the professional College. In general, these results reveal a profession predominantly practiced by young women (mean age 36 years), working preferably in the clinical area, whose theoretical orientation is mainly behavioral, located for the most part in urban areas, and chiefly working in private practice. The main current professional psychology fields in our country will be analyzed in detail, according to the following criteria: type of center where the professional works, intervention areas, and training required for professional practice. Some final reflections about the defense of our profession are commented upon, proposing training and accreditation strategies as the best way to face increasing problems about the entry of unqualified people into the profession.
\end{abstract}

\begin{abstract}
En este trabajo se pretende dar una visiớn de la evoluciớn y la situación actual de la Psicologia protesional española. Desde un punto de vista histórico, la profesión de psicólogo en España ha tenido un importante desarrollo cualitativo y cuantitativo desde los años 70 . Las bases sobre las que se ha apoyado dicho desarrollo son múltiples y de diverso carácter, aunque en este trabajo se resaltan dos: la implantación del título de Licenciado en Psicología y el desarrollo de una identidad profesional a través de la influencia que ejerce una organización como el Colegio Oficial de Psicólogos (COP). La descripción de la situación actual se lleva a cabo mediante el análisis de los resultados de los 6.765 colegiados que respondieron a la encuesta que el COP envió a la totalidad sus casi 28.000 miembros. Dichos resultados, con carácter general, dibujan una profesión de composición mayoritariamente femenina, aún joven (36 años de media) con una dedicación preferente al campo clínico, de orientación teórica predominantemente conductual, localizada fundamentalmente en áreas urbanas y con un ejercicio mayoritariamente privado. Posteriormente, y de forma pormenorizada, se analizan las principales especialidades protesionales de la Psicología que se ejercen actualmente en nuestro pais, atendiendo a los siguientes criterios: tipo de centro en el que se ejerce, ámbitos de intervención y formación necesaria para el ejercicio profesional. Por último, se apuntan algunas reflexiones finales sobre la defensa del espacio profesional, proponiendo la estrategia de la formación y la acreditación como mejor forma de afrontar los problemas del creciente intrusismo profesional.
\end{abstract}

Correspondence concerning this article should be addressed to the authors, Colegio Oficial de Psicólogos. Conde de Peñalver, $45-5^{\mathrm{a}}$ Planta. 28006 Madrid (Spain). 
Since the seventies, the development of professional psychology in Spain has been significant and surprising, both qualitatively and quantitatively. This is especially noteworthy taking into account the professional evolution in some neighboring countries, which have more scientific tradition, more population, and more per capita income. Many social, political, and economical justifications, as well as historical ones related to the development of psychology as a science, could account for this important progress. Probably, all of them are pertinent because such a scientific and professional phenomenon is always multi-determinate, and explanations are not usually simple and linear. However, this line of thought would divert us from our aim.

In this paper, we offer an overview of the development and the current reality of professional Spanish psychology, from the viewpoint of a scientific-professional organization such as the "Colegio Oficial de Psicólogos" [COP; Official College of Psychologists, also denominated The Spanish Psychological Association]. We will offer a brief review of the main facts and the people who made us what we are. We will then provide an outline of the current situation, ending with a short reflection on the present challenges and pending tasks.

We do not intend to offer a comprehensive analysis of the current reality of professional psychology in Spain. This type of exhaustive analysis would have to be versatile, whereas the authors' viewpoint is just that: one point of view among many possible ones. However, we will certainly adopt the COP perspective, and, sustained and limited by this perspective, we will attempt to offer a general blueprint of what Spanish psychologists are like and what they do when they practice their profession.

\section{Tradition}

Like other sciences, psychology in Spain and in the western world has traditionally been connected with philosophical reflection. Carpintero (1989) noted the great interest in psychological topics and their possible personal and social application in thinkers such as Luis Vives (1538) and, later on, Huarte de San Juan (1575) in his work Examen de Ingenios para las Ciencias [Examination of Talents for Sciences]. In this work, Huarte de San Juan attempted to elaborate a differential psychology for young people's career and vocational guidance (Siguán, 1978). Although these authors' thinking is acknowledged as a permanent framework and an important milestone for Spanish psychologists, there is a lack of continuity of this initial labor and a dramatic interruption until the beginning of the $20^{\text {th }}$ century. As Carpintero (1989, pp. 68-73) suggested, "there is a large gap between these Renaissance precedents and the first manifestations of a new tradition-now of scientific psychology-that begins to emerge at the end of the $19^{\text {th }}$ century and at the start of the $20^{\text {th }}$ century."
As regards scientific psychology, our country has received more than it created (Carpintero, 1989), probably because the evolution of psychology as an applied science occurred in industrialized contexts, with new and complex problems that were completely foreign to Spain until the mid- $20^{\text {th }}$ century, except for cities such as Barcelona, Madrid, and Bilbao. Specifically, in Barcelona and Madrid, a group of scientists became aware of the importance of scientific psychology and its possible applications in the educational freld and to account for human behavior, based on empiricism and physiological principles. This led them to contact various European scientific/psychological currents: Giner de los Ríos with W. Wundt and his laboratory in Lejpzig, and Dr. Simarro with P. Charcot in La Salpetier. Back in Madrid, Simarro founded the first anthropological laboratory, in fact, the first experimental psychology laboratory in Spain. In 1902, he achieved the first professorship in Experimental Psychology, created in the Science Faculty of the Complutense University, one of the first universities in the world to have such a faculty. His influence was noteworthy in young researchers, among whom were Cajal (a Nobel Prize winner for his work in neurophysiology), Rodríguez Lafora, and Achucarro, all of whom were subsequently extremely influential in the development of neurology and psychiatry in Spain (Siguán, 1978).

Other groups were also eager to introduce the new psychological trends in Spain, hoping, by means of an educational and pedagogical revolution, that relevant political and social changes could be made to create a modem country and a fairer society. In Madrid, the Free Institution of Teaching and, in Catalonia, a group motivated by their hopes for the rebirth of the Catalan culture, were inspired by the works of Claparède and Piaget to search for theoretical and scientific basis for their theories (Siguán, 1978).

The Catalonian group's dynamism and curiosity about applied psychology prompted the creation of the Learning Secretariat in Barcelona, which, four years Iater, became the Institute of Career Guidance, one of the first centers specifically dedicated to this activity.

During the twenties, official concern for educational and pedagogical renovation increased, and a law was passed to create the Institutes of Career Guidance in Madrid and Barcelona. This law actually only reflected the already existing tradition in this area in both cities. Dr. Mira y López took charge of the direction of the Institute in Barcelona. A psychiatrist and researcher of renowned prestige, he organized the selection and orientation services and designed specific personality tests to obtain more objective results.

In Madrid, Dr. José Germain carried out a similar task to Dr. Mira's in Barcelona. At this stage, psychological knowledge, applied by "non-psychologists," was flourishing. There was no formal psychology training, and self-teaching and the application of psychology by physicians, engineers, or educators predominated. These were our precedents, until the Civil War brutally checked the evolution of applied 
psychology in Spain. Fortunately, this interruption only lasted a few decades and never curbed the Group members' enthusiasm for and confidence in the role of psychology in our country. Carpintero (1989, pp. 68-73) summed up his admiration for Dr. Germain's task this way: "One cannot conceive of the preservation and recovery of the tradition of scientific psychology in Spain without the figure of José Germain and his tireless labor to reinstate psychology among us." Starting from a small Experimental Psychology Department of the "Consejo Superior de Investigaciones Cientificas" [Higher Council of Scientific Investigations], he established a nucleus/seed of subsequent development, whose collaborators, such as Yela, Pinillos, Secadas, Siguán, Pertejo, Álvarez Villar, Forteza, Pascual, among others (Carpintero), were the precursors of current scientific/applied psychology. This group's effort and dynamism inspired the creation of the School of Psychology in the University of Madrid in 1953. This center did not offer a Psychology Degree, but rather postgraduate training for graduate students wishing to specialize in psychology, and consequently, it trained psychology specialists without a suitable curriculum for applying psychological knowledge. This low-level specialization status lasted until the sixties, when the appropriate university approach was created to train psychologists from the start. At this point, teachers, students, and professionals were demanding the establishment of a proper curriculum, specific study plans, and independent psychology faculties. The emergence of psychology as a profession parallels Spain's marked industrialization process, which began in the seventies and gave rise to problems and social needs that could only be attended and understood from the framework of new multi-disciplinary concepts, where psychology was to play an important role.

\section{Psychology Degree (Licenciatura)}

Specific psychology training began in 1953, when the University of Madrid established the School of Applied Psychology. This center offered three fields: Pedagogy, Clinical Psychology, and Industrial Psychology. Prior to the foundation of this school, psychology in Spain was administered by selftaught individuals, with or without university training, who were enthusiastic about the development and evolution of psychological techniques and trends in other countries. The creation of the School only partially altered this situation. In the School, anyone with a degree in any university field could study postgraduate courses and later call themselves a psychologist. This was a slight change in the legal context, because any specialty diploma means that only those who obtain the diploma can use the "label." Nevertheless, although an improvement over the situation in which any layperson could call him- or herself a psychologist, the existence of this diploma did not prevent applied psychology from being applied by very poorly qualified individuals.
In 1964, a similar school was created in Barcelona, with two sections: a Pedagogical and Industrial section, and a Clinical Psychology section, in the Medicine Faculty. Access was limited to people with "Licenciaturas" [Degrees] in other studies, and the duration of the specialization was two years, as in Madrid.

In 1968, the Psychology Degree was established, sharing a two-year curriculum with Philosophy, and with another three years of specific studies. The way was clear to a degree with its own curriculum and specific faculties, separate from the Philosophy context.

In 1978, the first Psychology Faculty (Psychology Center) was created in the Complutense University of Madrid; a specific Psychology curriculum or suitable study plans were gradually established and scientific psychology began to achieve independent status, a determining factor in its development.

\section{Psychology Degree and Professional Practice}

With the new Psychology Degree, the relation between academic training and professional practice changed. For the first time, a degree specifically qualified individuals to practice professionally and required that anyone who wished to use the label of psychologist must have studied and completed the corresponding university credits. In our country, a degree protects the label and anyone wrongly using it is severely penalized. This apparently clear situation was not so evident before the Psychology Degree was established in 1968, or in other countries, where a university degree does not guarantee the exclusive use of the label and specific laws must be passed to protect it. On the other hand, in some countries, the use of the label is guaranteed exclusively to those who have achieved a state license, and a simple university degree is not sufficient (USA, Italy, Canada, etc.). In Spain, this situation may change in the future with the postgraduate fields, so that achieving a university degree by itself will not enable one to practice the various Psychology areas.

\section{Associationism and Practice}

As mentioned, in Spain, the achievement of the Psychology Degree qualifies for professional practice and establishes a series of rights and obligations for psychologists. The label becomes a brand and can only be used by those who have earned the Degree, at least, legally. However, the label would not be appropriately protected if the Spanish administration, with the approval of the Parliament, had not orchestrated the creation of the Official College of Psychologists (COP), in December of 1979. As with similar ones in Spain, the nature of this institution is semi-public. Its basic responsibilities are: (a) to coordinate the necessary 
means to adequately develop the profession, (b) to understand the adequate use of the label, (c) to protect the label from the entry of unqualified people into the profession, and (d) to ensure proper practice of the profession. Practicing psychologists must be affiliated and must abide by the deontological code approved by the organization members.

From the organizational viewpoint, the COP has its own statutes, approved by the Spanish government, and psychologists must obey its rules in their professional practice. Since its foundation, the COP has undergone a marked decentralization process, which has fostered the creation of various Autonomous Colleges that act independently in their respective territories, constitute their own Deontological Commissions, and are in charge of promoting psychology in all its facets.

COP membership has generally increased ever since its creation. Towards the end of the eighties, the total number of members was 2,358; in 1984, it was 11,403 ; in 1988, 17,261 , and in early 1999 , there were 27,787 members. The annual mean growth in the first five years was around 2,300, dropping to 1,300 in the next five years. This tendency is stable, reflecting the increase in students who finish psychology studies and in the faculties that prepare them professionally. Currently, there are over 40,000 students in the 20 Psychology Faculties in Spanish territory. At this point, we shall not attempt to assess the training of future professionals in our faculties. However, we emphasize the unquestionable need to expand practical training and exchanges with the professional world in order to prepare professionals who can offer quality solutions to the ever more complex demands of the work market.

In the last few years, Spanish society has expressed a great variety of demands, to which psychologists must respond appropriately. As a result, dozens of specialized areas, or rather mini-fields, have appeared. Many new intervention areas (i.e., Intervention in Crises and Disasters Psychology, Refugee-Intervention Psychology, Environmental Audit Psychology, etc.) have emerged, in addition to the classic intervention areas. There is currently no proper training for these new areas, either in Spanish or European psychology faculties. This radical transformation of our profession in the last ten years -in the number of professionals wanting to practice and the various types of interventions- is a cause of permanent tension between professional associationism and the academic perspective. A graduate, who is qualified to practice, will obviously expect to be able to find work in the labor market. We must find immediate solutions to a problem that will become extremely severe in the near future. This search for solutions had better be active and creative because, otherwise, the achievements of psychology will dwindle with time. The COP and the psychology faculties should face this challenge unless we wish to witness the paralysis of our profession. Hundreds of monographic associations have been created, interests have diversified, and interlocutors are disregarded.
In our opinion, this is bad for our profession because it reduces cohesion and psychologists' identification with their own group. Reality has shown that psychology is vigorous in countries where professional representativeness is in the hands of powerful organizations with sufficient means to create a solid professional identity.

\section{The Development of a Professional Identity}

The issue of the identity of professional groups is very important, both in the phase of their creation and in the implantation and maintenance in any social space.

In a very short period of time, Spanish psychologists have managed to self-define themselves as a group and to identify themselves as "psychologists," or members of a category. Certain conditions made them to wish to belong to this group: (a) an official Psychology Degree for professional qualification; (b) structured information taught at an appropriate location, by a certain professional; (c) the connection between this knowledge and certain actions that only psychologists are capable of performing, and the awareness of this knowledge as the foundation to study in depth other more complex areas; and (d) the thrill of sharing this experience and the feeling that, after this ritualized interval, they will be ready to join an acknowledged and legitimate association, such as the corresponding Professional College, through which they will access their profession and professional field. An organization to which to belong and to use as referent; an association that has created a deontological code, publishes informative bulletins, general and monographic journals; trains individuals, and guarantees communication among its colleagues by various means. In a word, a profession we should be proud to belong to.

However, this road to professional identity has its setbacks. Hernández (1984) cautioned all psychology sections of the hazard of the unbalanced rise in the amount of graduates and faculties, and the high percentage of unemployed psychologists with few prospects of finding work within their specialization. In this context, psychology graduates could find little justification to identify with and share the aims of a professional group whose labor expectations were, to say the least, obscure. Hernández stated that in 1982, the population of graduates was about 20,000 , with 7,277 COP members (with the exception of Catalonia). "A nucleus of professionals basically made up of women and young people: $63 \%$ women and $37 \%$ men. Approximately $40 \%$ were under 25 years old and $70 \%$ under 30 . Only $3 \%$ were over 45 years old" (Hernández, 1984, pp. 61-63). In addition, in the surveyed population, only 45 to $50 \%$ practiced psychology as their main activity. Thirteen to $18 \%$ practiced part-time and 11 to $15 \%$ practiced an unrelated activity. Twenty to $25 \%$ were unemployed. We emphasize that, although the number of unemployed psychologists is significant, the number of sub- and pluri- 
employed psychologists is no less so. This general overview of psychologists' labor situation, reported by Hernández, could lead us to conclude that the profession had stalled and was clearly in a process of involution. This was not the author's intention. His attitude was quite positive and hopeful, and he shared the conclusions of the "Seminar on the Third University Cycle and the Training of Psychologists" (1984), in the sense that the profession of psychologist was clearly installed in our country and professionals wishing to practice were finding more opportunities. Should we share this optimism? The answer may be found in the survey that Diaz and Quintanilla (1992) carried out for the COP. Ten years later, the profession of the psychologist in Spain was still quite young but the professionals were no longer so young. Thirty percent of the affiliated psychologists were under 30 and $15.4 \%$ were over 40 . The proportion of women had increased by $1 \%$ and was now $64 \%$, compared to $36 \%$ of men, and unemployment had decreased from $20-25 \%$ to $10.5 \%$, lower than in the general population. The remaining data of this study are generally similar to Hernández's (1982a, 1982b), although they are not comparable because of methodological and phrasing issues. The situation had changed for the better. Spanish psychologists were generally satisfied with their professional context.

Seven years later, we have once again sounded professional Spanish psychology to examine its evolution and current characteristics. Some of the relevant findings corroborate the tendencies of previous studies, other totally new ones reveal a more precise profile of the professional practice. They will be commented upon in the next section.

\section{Professional Psychology in Spain. Some Current Data}

As mentioned, professional psychology in Spain has grown ever since psychology courses were introduced in the Spanish University in the seventies. This course is comparable to that of other neighboring developed countries, with some distinctive features that make it more remarkable, such as the striking role of psychology in Traffic Safety or the consolidation of the training model and specialized degree in Clinical Psychology.

Several years ago, the COP sponsored two studies (Díaz \& Quintanilla, 1992; Quintanilla \& Berenguer, 1994) to analyze the work status of professional psychologists according to their distribution among the various specialized areas, the extent of their dedication, type of contract, reimbursement, etc. At that time, the number of affiliated professionals was about 20,000. Some of the most relevant data from the studies were published in Papeles del Psicólogo [Psychologists' Papers]; Quintanilla \& Berenguer, 1994) and in a special number of the journal Applied Psychology: An International Review (Quintanilla \& Díaz, 1994), which coincided with the $23^{\text {rd }}$ International Congress of Applied Psychology held in
Madrid in 1994. Since the publication of the results of that study, professional psychology has continued to expand in our country. The current number of members of the COP probably represents a high percentage of employed professional psychologists, because in Spain, membership is compulsory in order to practice. In addition to this constant membership increase, the different governments have gradually begun to put into practice more advanced social policies in education, health, or social services areas, and, along with Spain's economical improvement, the demand for private psychological services has also increased. The coincidence of these two factors (more psychologists and greater demand of public and private services) has produced an ever-increasing diversification of professional activity, which is of great interest to the professional College.

In the last three years, the COP has been gathering and mechanizing a large quantity of information about its members in order to know more about the sociodemographic and professional characteristics of psychological intervention in Spain. This data gathering is being carried out among new members and by surveying those who already belong to the organization, in a continuous process, with the aim of obtaining a true, permanently updated picture of the profession.

Most of the data provided hereunder proceed from the Professional Activity Survey (PAS) that was sent to 27,787 psychologists affiliated to the COP at the beginning of 1999. This is the source of the data about the field they practice, the type of center where they work, their theoretical orientation, and their professional activity. 6,765 survey responses returned to date were analyzed, which makes up about $25 \%$ of the total number of members. The remaining information (sex, age, address) is from the admission documents of the COP, and the results are from the analysis of the data provided by all the members of the COP.

We shall also provide the results from a study carried out by the COP in the Community of Valencia in 1998, to examine psychologists' functions in the well-established fields where there are more professionals (Clinical Psychology, Educational Psychology, Work and Organizational Psychology, and Social Intervention). This investigation was carried out by means of 722 interviews among the 4,000 affiliated members of that region. For the sample selection, a nonproportional sampling system and subsequent application of correcting coefficients were employed, so as to generalize the conclusions to the whole autonomous community. Despite the fact that this is a regional study, not a national one, the results can probably be generalized to the whole state, because there is no cause to assume that the professional functions in the Community of Valencia are radically different from those of the rest of the country, taking into account the relative cultural, legal, social, economical, and political homogeneity of the Spanish state.

We are aware that the data-gathering methodology employed with the PAS may be subject to bias, affecting 
validity and reliability of the results. With 6,765 survey responses to date (25\% of the total), the PAS data should be treated cautiously, since it is difficult to know the direction and amount of bias. Nevertheless, the large quantity of information gathered is relevant to examine the professional reality of psychology in Spain. Therefore, some of the more significant data of the current study are shown hereunder, emphasizing their partial and preliminary nature.

\section{A Basic Quantitative Overview of Spanish Professional Psychology}

In this section, we will comment upon some sociodemographic and professional data of the general features of the profession in Spain.

\section{$\operatorname{Sex}$}

In our country, psychology is practiced mainly by women. $72.58 \%$ of the affiliated professionals are women and only $27.42 \%$ are men. These numbers are slightly higher than earlier studies published in 1982 (Hernández, 1982a, 1982b) and in 1992 (Diaz \& Quintanilla, 1992), which revealed $59 \%$ and $41 \%$ of women and men, respectively, in the former, and $66 \%$ and $34 \%$, of women and men, respectively, in the latter study. This distribution is not unusual in our sociocultural environment and it also occurs in other Social and Health Sciences areas, which include psychology, and which also reveal a clear "feminization" process.

The distribution of this variable in the different fields is not uniform, as can be observed in Work Psychology, the Academic Area, Sports Psychology, and Military Psychology (see Table 1). In some of these areas (university faculty members, sports, armed forces), the percentage of the male labor force is higher than the female one, despite female predominance in professional psychology.

Table 1

Distribution by Sex in each of the Fields

\begin{tabular}{lcc}
\hline Field & Men & Women \\
\hline Clinical Psychology & $30 \%$ & $70 \%$ \\
Educational Psychology & $27 \%$ & $73 \%$ \\
Work Psychology & $44 \%$ & $56 \%$ \\
Social \& Community Psychology & $32 \%$ & $68 \%$ \\
Traffic Safety & $18 \%$ & $82 \%$ \\
Judicial Psychology & $32 \%$ & $68 \%$ \\
Academic Areas & $58 \%$ & $42 \%$ \\
Sports Psychology & $52 \%$ & $48 \%$ \\
Military Psychology & $63 \%$ & $38 \%$ \\
\hline
\end{tabular}

Note. Taken from Fernández Hermida, Berdullas Temes, Santolaya Ochando, and Muñiz (2000).
Age

The mean age of the 27,787 affiliates is 36.51 years ( $S D=8.14$ ), ranging from 22 to 68 years. These results reveal a basically young profession. $22.5 \%$ are under 30 and $30 \%$ are over 40 years old. These percentages are higher than those of Díaz and Quintanilla (I992), who found than only $29.8 \%$ were under 30 and $17.9 \%$ were over 40 years old.

\section{Fields}

Distribution by fields is shown in Table 2 . The great majority of psychologists practice Clinical Psychology, much more than the other fields. To interpret Table 2 correctly, readers are reminded that currently (September 1999), there is no State organization or any Administration that regulates the issue of specialist degrees in any of the psychology fields. The psychologists enter the various fields depending on their training, activity, and/or labor placement. Therefore, these data reflect psychologists' own analysis of their training and their work, not any private or public accreditation to practice as a specialist.

\section{Theoretical Orientation}

The cognitive-behaviorist theoretical orientation predominates in our country. Next are psychoanalysis-inspired and systemic orientations. The remaining orientations have a very minority representation, as is shown in Table 3.

Table 4 shows the distribution of the various theoretical orientations (in percentages) in each of the fields.

Without exception, the behaviorist models (CognitiveBehaviorist and Behavior Modification Models) predominate in all the fields. This is most obvious in Sports Psychology $(88,24 \%)$, whereas the lowest level is in Judicial Psychology $(57.37 \%)$.

The second most important theoretical orientation is Eclecticism. In all the fields, a significant percentage of

Table 2

Distribution by Fields

\begin{tabular}{lr}
\hline Field & Percentage \\
\hline Clinical Psychology & $68.36 \%$ \\
Educational Psychology & $15.29 \%$ \\
Work Psychology & $8.05 \%$ \\
Social \& Community Psychology & $4.40 \%$ \\
Traffic Safety & $1.63 \%$ \\
Judicial Psychology & $1.15 \%$ \\
Academic Areas & $0.51 \%$ \\
Sports Psychology & $0.35 \%$ \\
Military Psychology & $0.25 \%$ \\
\hline
\end{tabular}

Note. Taken from Fernández Hermida, Berdullas Temes, Santolaya Ochando, and Muñiz (2000). 
Table 3

Distribution by Theoretical Orientation

\begin{tabular}{lr}
\hline Theoretical Orientation & Percentage \\
\hline Cognitive-Behavioral Models (CBM) & $49.08 \%$ \\
Behavior Modification (BM) & $14.12 \%$ \\
Eclectic (E) & $12.80 \%$ \\
Psychoanalysis-inspired Psychology (PP) & $9.48 \%$ \\
Systemic Orientation (SO) & $5.45 \%$ \\
Humanist-inspired Psychology (HP) & $4.16 \%$ \\
Orthodox Psychoanalysis (OP) & $3.88 \%$ \\
Transactional Analysis (TA) & $0.57 \%$ \\
Gestalt Therapy (GT) & $0.20 \%$ \\
Phenomenological-Existential Models (PEM) & $0.20 \%$ \\
Other Orientations & $0.07 \%$ \\
\hline
\end{tabular}

Note. Taken from Fernández Hermida, Berdullas Temes, Santolaya Ochando, and Muñiz (2000).

psychologists are eclectic. The percentages vary from $9.69 \%$ in Clinical Psychology to $29.17 \%$ in the field of Traffic Safety.

The psychoanalytic models (Orthodox Psychoanalytical Orientation and Psychoanalysis-inspired psychotherapies) are more frequent among clinical psychologists (17.32\%) and Judicial Psychology specialists ( $8.20 \%$ ). The percentages in other fields are fairly low.

The Systemic Orientation is the first choice of Social and Community Psychology specialists. In other fields, its percentages were similar, ranging from $2.78 \%$ to $6.56 \%$, except in Sports Psychology and Military Psychology, where it was zero. The remaining orientations had very low percentages in all fields.
Table 5

Distribution According to Population Size

\begin{tabular}{lr}
\hline Population Size & Percentage \\
\hline Cities with more than 1 million inhabitants & $19 \%$ \\
Cities with 500.001 to 1 million inhabitants & $14 \%$ \\
Cities with 100.001 to 500.000 inhabitants & $28 \%$ \\
Cities with 50.001 to 100.000 inhabitants & $7 \%$ \\
Cities with less than 50.000 inhabitants & $32 \%$ \\
\hline
\end{tabular}

Note. Taken from Fernández Hermida. Berdullas Temes, Santolaya Ochando, and Muñiz (2000).

\section{Residence}

Psychologists still live predominantly in urban areas. Approximately $60 \%$ live in province capitals. However, as can be seen in Table 5, the highest percentage (32\%) of professionals live in small towns of less than 50,000 inhabitants.

Calculation of the distribution below the number of 50,000 inhabitants per town is difficult, due to the very large number of towns involved ( $98.5 \%$ of the country's towns). We examined the first 4,000 members of the 8,727 who lived in towns of less than 50,000 inhabitants and we found that approximately $11 \%$ lived in towns of less than 10,000 inhabitants. This is encouraging because it shows that the professional offer is becoming universal and is leaving the original urban areas.

However, with one caveat: the territorial distribution of a psychologist's residence cannot be taken an exact reference of her or his working place. Many live in "dorm-cities" or small towns close to large cities, with easier access to

Table 4

Distribution (in Percentages) by Field and Theoretical Orientation

\begin{tabular}{|c|c|c|c|c|c|c|c|c|c|c|}
\hline & \multicolumn{9}{|c|}{ Theoretical Orientation } & \multirow[b]{2}{*}{ PEM } \\
\hline & CBM & BM & $\mathbf{E}$ & $\mathrm{PP}$ & SO & HP & OP & TA & GT & \\
\hline Clinical Psychology & 48.00 & 14.29 & 9.69 & 12.17 & 5.34 & 4.35 & 5.15 & 0.58 & 0.24 & 0.19 \\
\hline Educational Psychology & 53.92 & 12.66 & 20.63 & 3.54 & 4.05 & 3.92 & 0.89 & 0.51 & 0.13 & 0.25 \\
\hline Work Psychology & 48.28 & 14.37 & 25.00 & 2.59 & 4.60 & 4.89 & 0.29 & 1.44 & & \\
\hline Social \& Community Psychology & 51.18 & 9.84 & 16.14 & 2.76 & 16.14 & 2.36 & 1.18 & 0.39 & & 0.39 \\
\hline Traffic Safety & 50.00 & 13.89 & 29.17 & 2.78 & 2.78 & 1.39 & & & & \\
\hline Judicial Psychology & 44.26 & 13.11 & 24.59 & 6.56 & 6.56 & 3.28 & 1.64 & & & \\
\hline Sports Psychology & 70.59 & 17.65 & 11.76 & & & & & & & \\
\hline Military Psychology & 60.00 & 6.67 & 26.67 & 6.67 & & & & 6.67 & & \\
\hline
\end{tabular}

Note. CBM = Cognitive-Behavioral Models; $\mathrm{BM}=$ Behavior Modification; $\mathbf{E}=$ Eclectic; $\mathbf{P P}=$ Psychoanalysis-inspired $\mathbf{P s y c h o l o g y} ;$ SO = Systemic Orientation; HP = Humanist-inspired Psychology; OP = Orthodox Psychoanalysis; TA = Transactional Analysis; GT $=$ Gestalt Therapy; PEM $=$ Phenomenological-Existential Models .

Taken from Fernández Hermida, Berdullas Temes, Santolaya Ochando, and Muñiz (2000). 
Table 6

Distribution by Field and Population Size

\begin{tabular}{|c|c|c|c|c|c|}
\hline Professional Field & $>1$ million & 500,001 to & $\begin{array}{l}100,001 \text { to } \\
1 \text { million }\end{array}$ & $\begin{array}{c}50,001 \text { to } \\
500,000\end{array}$ & $\begin{array}{r}<50,000 \\
100,000\end{array}$ \\
\hline Clinical Psychology & $24 \%$ & $14 \%$ & $36 \%$ & $8 \%$ & $17 \%$ \\
\hline Educational Psychology & $16 \%$ & $12 \%$ & $43 \%$ & $7 \%$ & $22 \%$ \\
\hline Work Psychology & $25 \%$ & $13 \%$ & $41 \%$ & $8 \%$ & $13 \%$ \\
\hline Social \& Community Psychology & $13 \%$ & $11 \%$ & $44 \%$ & $10 \%$ & $23 \%$ \\
\hline Traffic Safety & $14 \%$ & $12 \%$ & $31 \%$ & $11 \%$ & $31 \%$ \\
\hline Judicial Psychology & $18 \%$ & $14 \%$ & $40 \%$ & $11 \%$ & $17 \%$ \\
\hline Sports Psychology & $5 \%$ & $11 \%$ & $63 \%$ & $5 \%$ & $16 \%$ \\
\hline
\end{tabular}

Note. Taken from Fernández Hermida, Berdullas Temes, Santolaya Ochando, and Muñiz (2000).

Table 7

Distribution of COP Members According to Work Center

\begin{tabular}{|c|c|c|c|}
\hline Work Center & Percentage & Work Center & Percentage \\
\hline Individual Private Practice & $26.24 \%$ & Private Industry & $0.62 \%$ \\
\hline Private Office with Other Psychologists & $13.77 \%$ & Public Hospital Psychiatric Unit & $0.60 \%$ \\
\hline Private Office with Psychologists & & Private Academy & $0.55 \%$ \\
\hline and Other Professionals & $8.29 \%$ & Private University & $0.51 \%$ \\
\hline Private Professional Services Company & $4.25 \%$ & Private Therapeutic Community & $0.49 \%$ \\
\hline NGOs & $3.97 \%$ & Autonomic Health Administration & $0.47 \%$ \\
\hline Private Primary \& Secondary School & $3.85 \%$ & Institute of Social Services (INSERSO) & $0.43 \%$ \\
\hline Driver's License Check-up Center & $3.44 \%$ & Private Hospital Psychiatric Unit & $0.40 \%$ \\
\hline Public University & $3.44 \%$ & Intermediate Public Mental Health Center & $0.38 \%$ \\
\hline Town Hall & $2.95 \%$ & Private General Hospital & $0.34 \%$ \\
\hline Public Primary \& Secondary School & $2.70 \%$ & Public Therapeutic Community & $0.32 \%$ \\
\hline Academic Guidance Unit & & Private Outpatient Unit for Treatment of Drug- Addicts & s $0.32 \%$ \\
\hline of the Ministry of Education \& Science & $2.57 \%$ & Private General Medicine Center & $0.28 \%$ \\
\hline Private Center for the Psychologically Disabled & $2.10 \%$ & Other Public Services Companies & $0.28 \%$ \\
\hline Public Mental Health Center & $2.06 \%$ & Private Day-Care Hospital & $0.23 \%$ \\
\hline Town Hall Social Services Center & $2.04 \%$ & Intermediate Private Mental Health Center & $0.19 \%$ \\
\hline Regional Administrative Unit & $1.10 \%$ & Public Hospital Unit for Treatment of Drug-Addicts & $0.19 \%$ \\
\hline Public General Hospital & $0.96 \%$ & Public General Medicine Center & $0.17 \%$ \\
\hline Public Unit for Outpatient Treatment & & Public Day-Care Hospital & $0.17 \%$ \\
\hline of Drug-Addicts & $0.94 \%$ & Public Industry & $0.17 \%$ \\
\hline Non-Regional Public Administration & $0.91 \%$ & Neuropsychological Unit in Private Hospitals & $0.17 \%$ \\
\hline Public Professional Services Company & $0.89 \%$ & Public Research Center & $0.13 \%$ \\
\hline Other Private Services Companies & $0.87 \%$ & Public Personnel Selection Company & $0.13 \%$ \\
\hline Army & $0.83 \%$ & Private Primary Sector Company & $0.13 \%$ \\
\hline Non-Municipal Public Social Services Center & $0.81 \%$ & Private Mental Health Center & $0.11 \%$ \\
\hline Public Center for the Psychologically Disabled & $0.74 \%$ & Private Research Center & $0.11 \%$ \\
\hline Private Non-Municipal Social Services Center & $0.72 \%$ & Private Hospital Unit for Treatment of Drug- Addicts & $0.11 \%$ \\
\hline Private Personnel Selection Center & $0.72 \%$ & Private Primary Sector Company & $0.09 \%$ \\
\hline Administration of Justice & $0.64 \%$ & Neuropsychological Unit in Public Hospitals & $0.08 \%$ \\
\hline
\end{tabular}

Note. Taken from Fernández Hermida, Berdullas Temes, Santolaya Ochando, and Muñiz (2000). 
housing or better living conditions. If this were taken into account, the first items of Table 5 would probably increase. The best solution would be to have access to the working address, but this information is not yet available for all COP members. Therefore, the numbers are merely indicative of the territorial distribution of the profession.

The results of the territorial distribution of the main fields are shown in Table 6 . The relative majority of psychologists, regardless of their field, live in towns of 100,000 to 500,000 inhabitants, a size that coincides with that of most Spanish province capitals.

There seems to be no particular relation between location and professional field. The most homogeneous distribution in the whole territory was observed in the Traffic Safety field. Conversely, the specialists in Sports Psychology and Work Psychology are the opposite.

\section{Type of Work Center}

Spanish psychologists are still working mainly in private practice $(73 \%)$. However, there are a great variety of public centers in which they perform some professional activity. These different kinds of centers, from highest to lowest frequency, are shown in Table 7 . Individual private practice, or together with other professionals, is still the main activity, followed by the rest at a long distance. Readers are reminded that these data proceed from the Professional Activity Survey, to which approximately 6,800 psychologists responded. However, only 5,293 filled in the Type-of-Center space, and the remaining are mostly unemployed psychologists.

Table 8 shows the distribution of the different fields in the public and private areas. Clinical Psychology, Educational Psychology, Sports Psychology, Work Psychology, and Traffic Safety are mostly private activities. Judicial Psychology, Military Psychology, Social and Community Psychology, and the Academic Areas are preferably related to the public sector.

Table 8

Distribution by Field and Sector (Public/Private)

\begin{tabular}{lcc}
\hline Professional Field & Private & Public \\
\hline Clinical Psychology & $80 \%$ & $20 \%$ \\
Educational Psychology & $58 \%$ & $42 \%$ \\
Work Psychology & $73 \%$ & $27 \%$ \\
Social \& Community Psychology & $43 \%$ & $57 \%$ \\
Traffic Safety & $97 \%$ & $3 \%$ \\
Judicial Psychology & $42 \%$ & $58 \%$ \\
Academic Areas & $33 \%$ & $67 \%$ \\
Sports Psychology & $75 \%$ & $25 \%$ \\
Military / Police & $6 \%$ & $94 \%$ \\
\hline
\end{tabular}

Note. Taken from Fernắndez Hermida, Berdullas Temes, Santolaya Ochando, and Muñiz (2000).

\section{Data about the Various Application Fields}

In this section, we will comment upon some selected data of the majority professional fields. Specifically, the types of center where psychologists work in each of the fields and their main intervention sphere (i.e., the kind of problems or affairs they handle). We will also refer briefly to the training system in each of the fields.

It is difficult to divide professional psychology activity by fields, at least in our country. First, as mentioned, there is currently no regulated training system, or specific degree, or exclusive competencies for each of the fields (except for Clinical Psychology, which will be commented upon below). Nor is this contemplated in the near future. Therefore, the name "specialist" is based on the psychologist's own perception of her or his training, interests, and area of activity. The second difficulty concerns the inexact boundaries of each field in professional practice. This is obvious in the dispersed intervention areas of each "field," which means that "different" specialists will have many common intervention areas. For example, "neurotic disorders" are handled by $13.96 \%$ of the clinical psychologists, $1.31 \%$ of the educational psychologists, $0.67 \%$ of the work psychologists, $1.07 \%$ of the social and community psychologists, $1.95 \%$ of the judicial psychologists, $12.77 \%$ of the military psychologists, and $1.09 \%$ of the specialists in Traffic Safety. Only sports psychologists do not include this field of action.

In spite of this, the nucleus of each field is well defined. There is a close relationship between the self-assigned field and the type of center where the psychologist works and the problems handled, all of which is essential to describe the current reality of Spanish professional psychology. Therefore, the following sections will be structured according to the analysis by field.

\section{Clinical Psychology}

As mentioned, Clinical Psychology is the principal professional activity. Although it is mainly private (see Tables 8 and 9), its establishment in the public sector has constantly increased, diversified, and become consolidated.

As in the remaining psychology fields, there is currently no state entity or organism that regulates the Degree of Clinical Psychologist, although this situation may be temporary. In December 1998, a Royal Decree was passed, by which the Degree of Specialist in Clinical Psychology was created and access to it regulated. The rules and regulations are still being drafted and have not yet been published. Upon publication, the legal rules will apply and the first official Specialist Degrees will be issued.

The legal creation of the Degree of Specialist in Clinical Psychology is very important in both the public and private areas, although its functions are clearer in the public sector. There will be significant changes, even if only considering 
the legal consequences for professional practice. As soon as these official degrees are issued, the public administrations will require professionals to have the degree in order to practice as clinical psychologists in the public sector. The work and administrative situation of the psychologists in the National Health System will become similar to that of medical specialists. Psychologists practicing in the private sector will not be allowed to call themselves "Specialists in Clinical Psychology" unless they have this Degree, and probably, specialists will have more opportunities to offer their services to health administrations and insurance companies with labor agreements or contracts.

Currently, clinical psychologists practice in a variety of public and private centers. In all, 54 kinds of centers were mentioned, some having nothing in common with the health area (industry, personnel selection companies, or academic guidance units). Most of them also provide services in private practice, either singly or with other psychologists or professionals. In Table 9 are shown the kinds of center chosen by more than $2 \%$. Professional practice in the Public Health System is still somewhat scarce, although very dispersed (public mental health offices, drug-addict treatment units, $1.34 \%$; public hospitals, $1.28 \%$, etc.). The number of clinical psychologists who work in Non-Governmental Organizations (NGOs), probably in programs for drug addicts, the chronically ill, etc. is noteworthy. These associations are becoming increasingly more important in our society.

The list of clinical psychologists' intervention areas is extensive and heterogeneous, as expected from the variety of settings where they practice. "Neurotic disorders," personality disorders, and child behavior are the most frequent areas. Table 10 shows all the areas chosen by more than $2 \%$. There are 83 items, both clinical and nonclinical, on the complete list of preferred intervention areas, which indicates the polyvalence and prevalence of the "clinical outlook" among professional psychologists.

Regarding the functions of their professional activity, the study carried out in the Community of Valencia shows that assessment is still chosen the most frequently, although intervention or treatment reveal similar percentages (see Table 11).

In our country, training clinical psychologists has been traditionally carried out by either university training programs (Ph.D. or Master's Degree) or by unregulated private training. When the law to create the Field of Clinical Psychologist is passed, it may cause a strong reaction, because it establishes that the training process to obtain the specialist degree must be done in an Intern Program (Resident Intern Psychologist). These intern training programs (similar to medical fields), which began in some of the Autonomous Communities, currently depend on the State Administration for candidate selection and quality control of the teaching and training centers.
Table 9

Types of Centers where Clinical Psychologists Work

\begin{tabular}{lr}
\hline Type of Center & Percentage \\
\hline Individual Private Practice & $34.48 \%$ \\
Private Practice with Other Psychologists & $18.01 \%$ \\
Private Practice with Psychologists & \\
$\&$ Other Professionals & $10.69 \%$ \\
NGOs & $4.01 \%$ \\
Public Mental Health Center & $2.95 \%$ \\
Public University & $2.25 \%$ \\
\hline
\end{tabular}

Note. Taken from Fernández Hermida, Berdullas Temes, Santolaya Ochando, and Muñiz (2000).

Table 10

Distribution of Clintical Psychologists by Intervention Area

\begin{tabular}{lr}
\hline Intervention Area & Percentage \\
\hline Neurotic Disorders & $13.96 \%$ \\
Personality Disorders & $9.53 \%$ \\
Behavioral Disorders in Children & $6.97 \%$ \\
Psychosomatic Disorders & $6.11 \%$ \\
Marital Problems & $5.05 \%$ \\
Academic Learning Disorders & $4.57 \%$ \\
Psychotic Disorders & $4.47 \%$ \\
Eating Disorders & $3.96 \%$ \\
Family Problems & $3.32 \%$ \\
Sexual Disorders & $3.14 \%$ \\
Substance Addictions & $2.96 \%$ \\
Language Disorders & $2.15 \%$ \\
\hline
\end{tabular}

Note. Taken from Fernández Hermida, Berdullas Temes, Santolaya Ochando, and Muñiz (2000).

Table 11

Tasks Performed by Clinical Psychologists

\begin{tabular}{lr}
\hline Tasks & Percentage \\
\hline Assessment & $96.5 \%$ \\
Treatment & $96.3 \%$ \\
Diagnosis & $94.8 \%$ \\
Training & $60.6 \%$ \\
\hline
\end{tabular}

Note. Taken from Fernández Hermida, Berdullas Temes, Santolaya Ochando, and Muñiz (2000).

\section{Educational Psychology}

The educational area is the second most important among Spanish psychologists. This disagrees with the data from the first study by Díaz and Quintanilla (1992), in which Educational Psychology was the main activity, but it coincides with the study by the COP of Catalonia in their area, mentioned by Coll (1994). It also coincides with the 
percentage of students who decided to specialize in Clinical and Educational Psychology in the university (Coll). According to the data from various universities, approximately $70 \%$ of the students chose clinical subjects and only $15 \%$ chose educational ones.

One could speculate that psychologists' definition of themselves is not the same as what they do. However, upon analyzing clinical and educational psychologists' intervention areas (see Tables 10 and 13), the (self-assigned) specialization corresponds closely to what they actually do.

Most professional practice in this area is private, either by contract with an educational center or in private offices and centers. Most of the psychologists working in private educational centers are probably not employees, but autonomous workers with a service-provision contract, so that, in the long run, their work regime is comparable to that of psychologists in private practice, working either singly or with other psychologists. The percentage of educational psychologists with contracts with the public sector is higher than in the clinical area (see Table 8), usually within the framework of multidisciplinary teams that depend on the Administration (State or Autonomous) responsible for educational policy. As with Clinical Psychology, although percentages are slightly lower, self-defined educational psychologists work in a great variety of centers, with a total of 33 different types of centers. Table 12 shows the kinds of center chosen by more than $2 \%$.

As mentioned, the range of areas handled by educational psychologists is fairly representative of their field. Table 13 displays those that were chosen by more than $2 \%$.

Intervention areas are not so dispersed in this field as in Clinical Psychology, where the total amount of areas chosen by more than $2 \%$ added up to $66 \%$, whereas in Educational Psychology, the sum is $74 \%$. The self-assigned field is more accordance with the problems and topics handled.

Regarding the functions, the study from the Community of Valencia shows a high percentage of agreement among these specialists, as can be seen in Table 14. Educational Psychologists maintain close relationships with all the educational agents, although intervention and assessment are still the most frequently mentioned functions.

As with the rest of the fields in Spain, there is no regulated postgraduate training in Educational Psychology. There are postgraduate specialization offers from the university and from private enterprise. The proposals are fewer and less varied than in Clinical Psychology. The COP supports the initiative to establish a postgraduate training and accreditation procedure that would guarantee qualification in this field, with maximum professional and institutional consensus and acknowledgement.

\section{Work Psychology}

Work Psychology is the third most preferred field for Spanish psychologists. As with most fields, professional
Table 12

Distribution of Educational Psychologists by Type of Center

\begin{tabular}{lr}
\hline Type of Center & Percentage \\
\hline Private Primary and Secondary Education & $17.81 \%$ \\
Academic Guidance Unit of the MEC & $14.16 \%$ \\
Private Individual Practice & $13.14 \%$ \\
Public Primary and Secondary Education & $12.70 \%$ \\
Private Individual Practice with Other Psychologists & $8.76 \%$ \\
Private Individual Practice with & \\
Other Psychologists and Professionals & $4.53 \%$ \\
Town Hall & $4.23 \%$ \\
Public University & $4.09 \%$ \\
Private Center to Attend the Psychologically Disabled & $3.07 \%$ \\
NGOs & $2.77 \%$ \\
Driver's' License Check-Up Center & $2.77 \%$ \\
\hline
\end{tabular}

Note. $\mathrm{MEC}=$ Ministry of Education and Sciences.

Taken from Fernández Hermida, Berdullas Temes, Santolaya Ochando, and Muñiz (2000).

Table 13

Distribution of Educational Psychologists by Intervention Area

\begin{tabular}{lr}
\hline Intervention Area & Percentage \\
\hline Academic Learning Disorders & $15.57 \%$ \\
Academic and Vocational Guidance & $14.00 \%$ \\
School Failure & $7.90 \%$ \\
Study Techniques & $7.71 \%$ \\
Language Disorders & $6.81 \%$ \\
Behavior Problems in Children & $6.25 \%$ \\
Behavior Problems in the Classroom & $4.87 \%$ \\
Developmental Retardation & $4.79 \%$ \\
Training & $2.58 \%$ \\
Career Guidance & $2.10 \%$ \\
\hline
\end{tabular}

Note. Taken from Fernández Hermida, Berdullas Temes, Santolaya Ochando, and Muñiz (2000).

Table 14

Tasks Performed by Educational Psychologists

\begin{tabular}{lr}
\hline Tasks & Percentage \\
\hline Intervention & $91.4 \%$ \\
Assessment & $91.0 \%$ \\
Detection and Prevention & $83.5 \%$ \\
Parent Counseling & $82.8 \%$ \\
Teacher Counseling & $74.6 \%$ \\
Psychopedagogic Guidance & $67.7 \%$ \\
Collaboration with Special Education & \\
Teachers and Tutors & $56.6 \%$ \\
Counseling the Teaching Center Directive Teams & $55.6 \%$ \\
\hline
\end{tabular}

Note. Taken from Femández Hermida, Berdullas Temes, Santolaya Ochando, and Muñiz (2000). 
practice is basically private (see Tables 8 and 15), however, via professional services companies, in contrast to Clinical or Educational Psychology, where private consulting offices predominate. Within the public area, the University (i.e., professors of Work Psychology-related topics) offers the most posts. Jobs in the Administration or in public industry (which is rapidly becoming extinct) are much less frequent.

The intervention areas most frequently chosen by work psychologists coincide with their field. The most frequently chosen task was "Personnel selection," followed by "Training" and "Career Guidance." Table 16 shows all the options chosen by more than $2 \%$. As with Educational Psychology, there was marked dispersion in the remaining $25 \%$ of the choices not displayed on Table 16, although it does not reach the level of Clinical Psychology.

Table 15

Distribution of Work Psychologists by Work Center

\begin{tabular}{lr}
\hline Work Center & Percentage \\
\hline Private Professional Services Company & $30.58 \%$ \\
Private Individual Practice & $9.64 \%$ \\
Public University & $6.06 \%$ \\
Private Personnel Selection Company & $5.51 \%$ \\
Private Industry & $5.51 \%$ \\
Town Hall & $4.68 \%$ \\
Other Private Professional Services Companies & $4.41 \%$ \\
Non-regional Public Administration & $4.13 \%$ \\
Public Professional Services Company & $3.86 \%$ \\
Private Practice with Psychologists & \\
and Other Professionals & $2.75 \%$ \\
NGOs & $2.48 \%$ \\
Private Practice with Other Psychologists & $2.20 \%$ \\
Regional Administrative Unit & $2.20 \%$ \\
\hline
\end{tabular}

Note. Taken from Fernández Hermida, Berdullas Temes, Santolaya Ochando, and Muñiz (2000).

Table 16

Distribution of Work Psychologists by Intervention Areas

\begin{tabular}{lr}
\hline Intervention Area & Percentage \\
\hline Personnel Selection & $20.58 \%$ \\
Training & $20.11 \%$ \\
Career Guidance & $6.57 \%$ \\
Communication & $5.63 \%$ \\
Work Health & $5.03 \%$ \\
Quality Management & $4.36 \%$ \\
Research and Teaching in Work Psychology & $3.49 \%$ \\
Ergonomics & $3.15 \%$ \\
Change Management & $2.82 \%$ \\
Client Care & $2.41 \%$ \\
\hline
\end{tabular}

Noıe. Taken from Fernândez Hermida, Berdullas Temes, Santolaya Ochando, and Muñiz (2000).
In the study carried out in the Community of Valencia, there was high agreement in the functions of these professionals. Thus, $72.7 \%$ administer selection tests, define candidate profiles, and perform selection and assessment interviews. And $63.6 \%$ write up various kinds of reports, and $38.8 \%$ design reception plans for company newcomers.

Both the University and private enterprise offer work psychologists a great variety of postgraduate training. After obtaining their Psychology Degree, they can either study Master's or Ph.D. courses in Work Psychology or carry out some other kind of postgraduate studies related to the world of enterprise, where a Psychology Degree is not a specific requirement (for example, Human Resources, Enterprise Direction and Administration, etc.).

As in Educational Psychology, the COP is currently promoting a process for the elaboration of a training program and accreditation system in this professional field.

\section{Social and Community Psychology}

Social and Community Psychology is the fourth most important professional specialization for psychologists. If we extend the percentage from the Professional Activity Survey (4.40\%) onto the 27.727 COP members, then approximately 1.223 psychologists work in this professional field or have special affinity with it.

This field is carried out basically in the public sector, although there is a fairly important private sector (43\%). In Spain, the Social Services have expanded in the last decades with the resulting the increase of public employment in this sector. Most centers depend on the local city councils. The

Table 17

Distribution of Psychology Specialists in Social Intervention by Work Center

\begin{tabular}{lr}
\hline Work Center & Percentage \\
\hline Municipal Social Services Center & $15.04 \%$ \\
Town Hall & $13.27 \%$ \\
NGOs & $12.39 \%$ \\
Public Non-Municipal Social Services Center & $6.19 \%$ \\
Private Professional Services Company & $5.75 \%$ \\
Public University & $4.87 \%$ \\
Regional Administrative Unit & $4.42 \%$ \\
Private Practice with Other Psychologists & \\
and Other Professionals & $4.42 \%$ \\
Private Center for the Psychologically Disabled & $3.98 \%$ \\
Private Non-Municipal Social Services Center & $3.10 \%$ \\
Individual Private Practice & $3.10 \%$ \\
Public Professional Services Company & $2.65 \%$ \\
Other Public Services Companies & $2.21 \%$ \\
Drivers' License Check-Up Center & $2.21 \%$ \\
\hline
\end{tabular}

Note. Taken from Fernández Hermida, Berdullas Temes, Santolaya Ochando, and Muñiz (2000). 
types of centers were these specialists work is seen in Table 17 , which shows only those centers where at least $2 \%$ of these specialists are working. The last item, referring to "Driver's License Check-up Centers," is noteworthy, because in these centers, the activities are only generically related to Social and Community Psychology. If we exclude this kind of center, the remaining figures represent the type of centers where over $80 \%$ of the social and community psychologists work.

The intervention areas are mostly highly related to the preferential field topics. However, there is great dispersion as compared with the rest of the fields (see Table 18). A plausible explanation for this may be the difficulty of specifying these professionals' social policy goals, because they must play many roles that are different from those of their field (Clinical, Educational, Work Psychology, etc.).

Regarding functions, according to the study from the Community of Valencia, $68.4 \%$ design preventive programs and programs for improving social conditions of target populations; $59.8 \%$ establish and maintain collaboration channels with available services and resources; $58.2 \%$ inform, council, or guide users, their families, and collectives about their rights, duties, and resources; $51.6 \%$ assess programs designed to detect population needs; and $45,1 \%$ elaborate or promote popularization campaigns or campaigns to sensitize people.

The training these specialists receive is no different from that of other fields. There is a Master's Degree or a Ph.D. that depend on public universities, and a non-university proposal offered public and private institutions. The training offer from the private section is scarcer than in other professional psychology fields (Clinical, Educational, or Work Psychology), with the institutional offer by public administration and professional organizations clearly predominating.

\section{Traffic Safety Psychology}

Traffic Safety is the fifth most numerous specialization field, according to the Professional Activity Survey. Its distinctive feature is that the psychologist's intervention is legally required for psychological assessment, and cannot be eliminated or carried out by another professional. This has consolidated the psychologist's role in this area more than in others.

The centers where these specialists work are welldefined: the great majority $(92.39 \%)$ works in private centers where drivers get their check-up. Their task is to determine whether the individuals who want to renew their driver's license possess the psychological conditions required by law. The percentage of psychologists who specialize in Traffic Safety in the public sector is very small (3\%).

The estimation of 450 to 500 psychologists in this field does not indicate its true importance in our country. Back in 1994 (Blasco, 1994), there were about 2,000 psychologists working in Driver's License Check-up Centers and although this number has probably not increased much, it is far from the 500 estimated in the current survey. A plausible explanation for this disparity is that, in many cases, employment in these centers is not full-time and the professional may therefore consider it secondary. Thus, this professional would not register as a Traffic Safety specialist in the survey, in spite of working in one of these centers.

The results obtained in the part of the survey referring to the Intervention Area (see Table 19) support this statement. In the survey, members were required to choose the three intervention fjelds they considered the most related to their professional activity. Most of these specialists chose items unrelated to their specialization field, which dispersed the results (with most of the percentages below $2 \%$ ), despite the fact that the majority choice is Traffic Safety. Taking

Table 18

Distribution of Psychology Specialists in Social Intervention by Area

\begin{tabular}{lc}
\hline Intervention Area & Percentage \\
\hline Social Services and Family and Infancy & $11.73 \%$ \\
General Social or Community Services & $10.40 \%$ \\
Social Services and Handicapped, Deficient, & \\
and Disabled People & $6.80 \%$ \\
Training & $4.13 \%$ \\
Family Disorders & $4.13 \%$ \\
Social Services and Women & $3.60 \%$ \\
Career Guidance & $3.07 \%$ \\
Drug Addiction & $3.07 \%$ \\
Judicial Psychology and Minors & $2.93 \%$ \\
Antisocial Behavior & $2.80 \%$ \\
Research and Teaching in Social Psychology & $2.67 \%$ \\
Children's Behavioral Disorders & $2.67 \%$ \\
Personnel Selection & $2.40 \%$ \\
Social Services and Dependence on Drugs & $2.40 \%$ \\
Social Services and the Elderly & $2.40 \%$ \\
Social Services and Youth & $2.27 \%$ \\
Developmental Retardation & $2.27 \%$ \\
\hline
\end{tabular}

Note. Taken from Fernández Hermida, Berdullas Temes, Santolaya Ochando, and Muñiz (2000).

Table 19

Distribution of Psychology Specialists in Traffic Safety and Intervention Areas

\begin{tabular}{lr}
\hline Intervention Area & Percentage \\
\hline Traffic Safety & $42.62 \%$ \\
Children's Behavior Problems & $4.92 \%$ \\
Academic Learning Disorders & $3.81 \%$ \\
Academic and Vocational Guidance & $2.71 \%$ \\
Marital Problems & $2.19 \%$ \\
Language Disorders & $2.19 \%$ \\
\hline
\end{tabular}

Note. Taken from Fernández Hermida, Berdullas Temes, Santolaya Ochando, and Muñiz (2000). 
into account the items chosen, there seems to be a significant group of individuals from the survey who combine their work in Traffic Safety with Educational Psychology.

Access to employment in this professional field is unregulated; there is no established or accredited training procedure. The meager training offer in Traffic Safety is mostly limited to several universities (Valencia, Barcelona, Madrid) that have influence in this field because of research groups and Master's courses. There is no appreciable training offer from the private sector.

\section{Judicial Psychology}

Specialists in Judicial Psychology are the sixth most numerous group, according to the results of the survey. Currently, most of these professionals work in prisons and courthouses, in the public sector, and their numbers are steadily increasing (see Table 20). There is also an important private sector, related to making expert reports by request of lawyers, or even of judges, and this is done from private practice.

There is a noteworthy presence of "self-denominated" judicial psychologists in outpatient clinical units (drug addictions or mental health), although the proportion is low. Probably, these professionals perform experts' tasks, with frequent Court reports, rather than therapies, in which case, they are more related to Judicial Psychology than to Clinical Psychology.

The main intervention areas (see Table 21) are related to the work performed by psychologists in the Administration of Justice and can be grouped around two principal axes: Judicial Psychology and Minors in Family Courts, and Forensic Psychology in Penal Law.

In general, the intervention areas and the main field themes are closely linked. There is less dispersion than in other fields, with many application fields that were not chosen even once. These results indicate a well-defined field with professionals concentrating on a specific full-time professional task.

Training offers in Judicial Psychology proceed mainly from the university and private environment. Despite there being no regulated training system, in the last few years, the COP has been demanding minimum training, accredited by the Institution, to become a member of the various forensic expert-witness teams created in the territorial courts. These expert witnesses are used by the Courts when they require experts to participate in Court cases.

\section{Sports Psychology}

Sports Psychology is a minority activity within the profession, and its practice is eminently private. Only $25 \%$ work in the public sector, in city councils, in units depending on the autonomous governments, and in the University. In the private sector, these specialists are basically autonomous, working in private offices, although some are employed by sports, social, or recreation entities (see Table 22).
Table 20

Distribution of Judicial Psychologists by the Work Center

\begin{tabular}{lr}
\hline Work Center & Percentage \\
\hline Administration of Justice & $44.90 \%$ \\
Private Individual Practice & $12.24 \%$ \\
Private Practice with Psychologists and Other Professionals & $8.16 \%$ \\
Private Practice with Other Psychologists & $8.16 \%$ \\
NGOs & $4.08 \%$ \\
Private Professional Services Company & $4.08 \%$ \\
Municipal Social Services Center & $4.08 \%$ \\
Public University & $2.04 \%$ \\
Private University & $2.04 \%$ \\
Private Unit for Outpatient Treatment of Drug-Addicts & $2.04 \%$ \\
Regional Administrative Unit & $2.04 \%$ \\
Town Hall & $2.04 \%$ \\
Public Outpatient Mental Health Center & $2.04 \%$ \\
Non-Regional Public Administration & $2.04 \%$ \\
\hline
\end{tabular}

Note. Taken from Fernández Hermida, Berdullas Temes, Santolaya Ochando, and Muñiz (2000).

Table 21

Distribution of Judicial Psychologists by Intervention Area

\begin{tabular}{lc}
\hline Intervention Area & Percentage \\
\hline Judicial Psychology and the Minor & $19.51 \%$ \\
Forensic Psychology & $17.07 \%$ \\
Mediation & $7.32 \%$ \\
Victimology & $5.85 \%$ \\
Antisocial Behavior & $4.39 \%$ \\
Criminology & $3.90 \%$ \\
Penitentiary Psychology & $3.41 \%$ \\
Personality Disorders & $2.93 \%$ \\
Drug Addiction & $2.93 \%$ \\
Expert Opinion & $2.44 \%$ \\
Social Services and Family and Infancy & $2.44 \%$ \\
Family Disorders & $2.44 \%$ \\
Marital Problems & $2.44 \%$ \\
\hline
\end{tabular}

Note. Taken from Fernández Hermida, Berdullas Temes, Santolaya Ochando, and Muñiz (2000).

Table 22

Distribution of Sports Psychologists by the Work Center

\begin{tabular}{lr}
\hline Work Center & Percentage \\
\hline Private Individual Practice & $37.50 \%$ \\
Private Professional Services Company & $18.75 \%$ \\
Regional Administrative Unit & $12.50 \%$ \\
Private Practice with Psychologists and Other Professionals $12.50 \%$ \\
Public University & $6.25 \%$ \\
Private Practice with Other Psychologists & $6.25 \%$ \\
Town Hall & $6.25 \%$ \\
\hline
\end{tabular}

Nore. Taken from Fernández Hermida, Berdullas Temes, Santolaya Ochando, and Muñiz (2000). 
Table 23

Distribution of Sports Psychologists by Intervention Area

\begin{tabular}{lc}
\hline Intervention Area & Percentage \\
\hline Direct Intervention in High Performance Sports & $20.63 \%$ \\
Intervention in Sports Training Schools & $20.63 \%$ \\
Teaching and Training Sports Specialists & \\
and Technicians & $19.05 \%$ \\
Research and/or Teaching in Sports Psychology & $14.29 \%$ \\
\hline
\end{tabular}

Note. Taken from Fernández Hermida, Berdullas Temes, Santolaya Ochando, and Muñiz (2000).

As in Judicial Psychology, these specialists have welldefined intervention areas, choosing mainly items directly related to their field (see Table 23). Apparently, "sports specialists" are totally dedicated to Sports Psychology and do not combine this activity with interventions in other fields.

Training in this field is mainly from private sources, although in the last two years, some universities (Barcelona and Valencia) are offering Master's Degrees and postgraduate courses. Currently, no regulated training is established for these specialists.

Some Final Remarks about the Perspectives and Future Trends of Professional Psychology in Spain

In the above-mentioned data and tables, the number of professionals and the variety of intervention areas in professional psychology in Spain have greatly increased in the last few years. Some of the trends indicated in previous studies have become consolidated, and other data are now seen from a different viewpoint. For instance, the increasing feminization and diversification of the profession is obvious. Some work areas are still preeminent, such as Clinical Psychology, followed by Educational Psychology and Work Psychology. Others are becoming consolidated (Traffic Safety, Sports, etc.) with the subsequent demand for specific training and professional profiles. This greater amount of professional alternatives, together with a close scientificprofessional link, is characteristic of Spanish professional psychology. This is especially noteworthy when compared with the implantation of professional psychology in neighboring countries, where frequently university and professional environments are clearly separate, with little interaction among them.

However, certain factors and their consequences must be analyzed so that the development of the profession does not come to a halt, but is definitely consolidated, turning out professionals capable of functioning with high-level quality in the various intervention areas. As mentioned, these factors currently affecting our profession and its social image are the outcome of the extraordinary professional development and diversification. Specifically, we are referring to opening up new professional areas without a clear perception of what psychology has to offer in these areas, and, as a consequence, the entrance of many unqualified individuals in the profession. There are several reasons for this: recently created professions move into these new professional areas in an attempt to establish their own identity; various professional intervention areas are often not well-differentiated, causing conflict between the different psychology fields; and postgraduate training is inadequate for the emerging professional needs of psychologists.

These problems are clearly not limited to Spain and can be observed in other European countries. However, we believe that the extraordinary capacity of professional psychology to permeate Spanish society has made these problems more crucial than in other countries, where there is less professional diversification. The so-called entry of unqualified people into the profession -i.e., the invasion of specific functions of a profession by other professionals with different degrees (which is also observed in other professions, for example, the blurred boundaries between odontologists and dentists, enterprise administrators and economists, or lawyers and administrative managers in some activities)- will foreseeably increase over time. This is due to market requirements and the demand and supply relationship, which allows individuals with certain university degrees to control a particular work area.

This situation is influenced by liberal political ideas, currently dominant in the Spanish market, which means that only the more skilled professionals, who offer high-quality interventions and are capable of satisfying user's demands, will be able to enter the working world massively.

Within this context of poor definition and fighting for professional space, psychologists must raise their competence level through formal and scientifically solid postgraduate training, which should be closely related to the social needs that create the demand for their services. This training should, in turn, have an associated "brand" that clearly identifies qualified professionals, so they can be easily recognized by possible clients and by Society, which watches over the quality of the services offered to its citizens.

The Professional College of Psychologists cannot remain passive about the instrumentation of this postgraduate training and accreditation process. With the aim of uniting the profession, joining the professional to the academic, the COP published a monographic volume in 1998 (Colegio Oficial de Psicólogos, 1998) on the professional profiles of psychologists designed to orientate professionals and society about the functions and limits of our profession. In this volume, the functions of the profession were delimited within each specialization, and, in some fields, minimum training requirements for accreditation as a specialist were established. 
This is just the first step. In the next few years, agreements for the accreditation of specialized training will be established with private and public entities, and we will attempt to obtain official acknowledgement of specialist degrees, similar to that established for the Degree of Specialist in Clinical Psychology. On the other hand, the COP should establish the accreditation procedures for all the professional psychology fields and constitute the competent collegial organs for their initiation.

This will be a long process, but we are determined to carry it out. Only by striving for professional excellence and its acknowledgement can we preserve and extend the professional areas that have developed in the last few years. Likewise, psychology as a science will develop the best in an atmosphere where professional psychology is fully implanted and socially acknowledged. These two ideas guide out aims and inspite future projects.

\section{References}

Blasco, R.D. (1994). Psychology and road safety. Applied Psychology: An international review, 43, 313-322.

Carbonero, I,, \& Fernández Hermida, J. (1995). Perfiles del psicólogo, psicología clínica y de la salud. Papeles del Psicólogo, $63,49-52$.
Carpintero, H. (1989). EI psicólogo en España: notas históricas sobre su desarrollo profesional. Papeles del Psicólogo, 36/37, 68-73.

Colegio Oficial de Psicólogos (1998). Perfles profesionales del psicólogo. Madrid: Author.

Coll, C. (1994). School and educational psychology. Applied Psychology: An International Review, 43, 175-19l.

Díaz, R., \& Quintanilla, I. (1992). La identidad profesional del psicólogo en el Estado Español. Papeles del Psicólogo, 52, 22-74.

Fernándæz Hermida, J.R., Berdulles Temes, M., Santolaya Ochando, F., \& Muñíz, J. (2000). La situación de los psicólogos colegiados en el ambito del estado. Unpublished manuscript.

Hernández, A. (1982a). La situación laboral de los psicólogos (1). Papeles del Colegio, 6, 31-48.

Hernández, A. (1982b). La situación laboral de los psicólogos (2). Papeles del Colegio, 6, 43-49.

Hernández. A. (1984). La Psicología como profesión. Papeles del Psicólogo, 16/17, 61-63.

Quintanilla, I., \& Berenguer, G. (1994). La imagen del psicólogo en el Estado Español. Papeles del Psicólogo, 58,41-68.

Quintanilla, I., \& Díaz, R. (1994). Some demographic and economic characteristics of practitioners. Applied Psychology: An international review, 43, 151-155.

Siguán, M. (1978). La enseñanza universitaria de la psicología en España. Anuario de Psicología, 19, 125-137. 